\title{
Mass-Producible 2D-MoS 2 -Impregnated Screen-Printed Electrodes That Demonstrate Efficient Electrocatalysis toward the Oxygen Reduction Reaction
}

\author{
Samuel J. Rowley-Neale, ${ }^{\dagger, \ddagger}$ Graham C. Smith, ${ }^{\S}$ and Craig E. Banks ${ }^{* \dagger, \ddagger 0}$ \\ ${ }^{\dagger}$ Faculty of Science and Engineering and ${ }^{\ddagger}$ Manchester Fuel Cell Innovation Centre, Manchester Metropolitan University, Chester \\ Street, Manchester M1 5GD, U.K. \\ ${ }^{\S}$ Faculty of Science and Engineering, Department of Natural Sciences, University of Chester, Thornton Science Park, Pool Lane, Ince, \\ Chester $\mathrm{CH} 2$ 4NU, U.K.
}

\section{Supporting Information}

ABSTRACT: Two-dimensional molybdenum disulfide (2D-MoS ${ }_{2}$ ) screen-printed electrodes (2D-MoS - SPEs) have been designed, fabricated, and evaluated toward the electrochemical oxygen reduction reaction (ORR) within acidic aqueous media. A screen-printable ink has been developed that allows for the tailoring of the $2 \mathrm{D}-\mathrm{MoS}_{2}$ content/ mass used in the fabrication of the $2 \mathrm{D}-\mathrm{MoS}_{2}$-SPEs, which critically affects the observed ORR performance. In comparison to the graphite SPEs (GSPEs), the 2D-MoS ${ }_{2}$-SPEs are shown to exhibit an electrocatalytic behavior toward the ORR which is found, critically, to be reliant upon the percentage mass incorporation of $2 \mathrm{D}-\mathrm{MoS}_{2}$ in the $2 \mathrm{D}-\mathrm{MoS}_{2}-\mathrm{SPEs}$; a greater percentage mass of $2 \mathrm{D}-\mathrm{MoS}_{2}$ incorporated into the $2 \mathrm{D}-\mathrm{MoS}_{2}$ SPEs results in a significantly less electronegative ORR onset potential and a greater signal output (current density). Using optimally fabricated

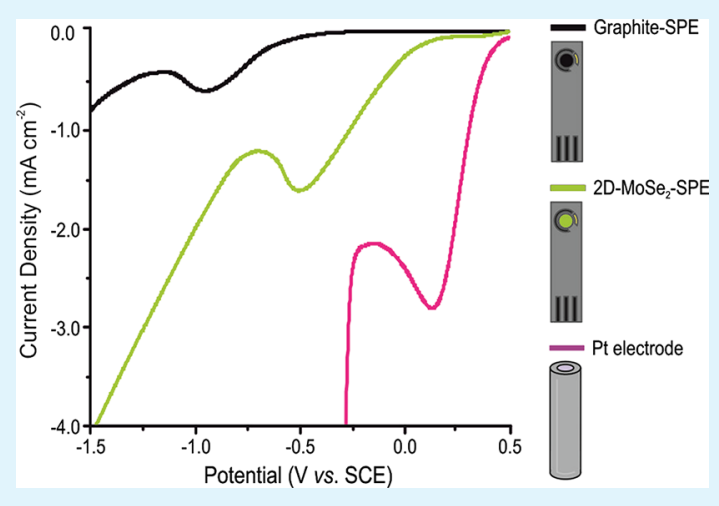
$2 \mathrm{D}-\mathrm{MoS}_{2}$-SPEs, an ORR onset and a peak current of approximately +0.16 $\mathrm{V}$ [vs saturated calomel electrode (SCE)] and $-1.62 \mathrm{~mA} \mathrm{~cm}^{-2}$, respectively, are observed, which exceeds the $-0.53 \mathrm{~V}$ (vs SCE) and $-635 \mu \mathrm{A} \mathrm{cm}^{-2}$ performance of unmodified G-SPEs, indicating an electrocatalytic response toward the ORR utilizing the 2D$\mathrm{MoS}_{2}$-SPEs. An investigation of the underlying electrochemical reaction mechanism of the ORR within acidic aqueous solutions reveals that the reaction proceeds via a direct four-electron process for all of the $2 \mathrm{D}-\mathrm{MoS}_{2}-\mathrm{SPE}$ variants studied herein, where oxygen is electrochemically favorably reduced to water. The fabricated $2 \mathrm{D}-\mathrm{MoS}_{2}$-SPEs are found to exhibit no degradation in the observed achievable current over the course of 1000 repeat scans. The production of such inks and the resultant mass-producible $2 \mathrm{D}-\mathrm{MoS}_{2}$-SPEs mitigates the need to modify post hoc an electrode via the drop-casting technique that has been previously shown to result in a loss of achievable current over the course of 1000 repeat scans. The $2 \mathrm{D}-\mathrm{MoS}_{2}-\mathrm{SPEs}$ designed, fabricated, and tested herein could have commercial viability as electrocatalytic fuel cell electrodes because of being economical as a result of their scales of economy and inherent tailorability. The technique utilized herein to produce the $2 \mathrm{D}-\mathrm{MoS}_{2}$-SPEs could be adapted for the incorporation of different 2D nanomaterials, resulting in SPEs with the inherent advantages identified above.

KEYWORDS: molybdenum disulphide $\left(\mathrm{MoS}_{2}\right)$, oxygen reduction reaction, hydrogen economy, modified inks, $2 \mathrm{D}$ electrochemistry, screen-printed electrodes

\section{INTRODUCTION}

The creation of a global energy system, where economic growth is decoupled from increased greenhouse gas emissions and other air pollutants, has been the aim of researchers since the implications of anthropogenic climate change and poor air quality issues were realized. Hydrogen fuel cells, in particular, the proton exchange membrane fuel cells (PEMFCs), ${ }^{1,2}$ have offered less polluting alternatives to many fossil-fuel (FF)-based energy generation technologies. A PEMFC is capable of producing current because of hydrogen oxidation occurring at the anode and the oxygen reduction reactions (ORR) occurring at the cathode. ${ }^{3-6}$
The ORR is typically the rate-limiting reaction in the creation of energy by PEMFCs owing to its large kinetic inhibition attributed to the strength of the (di)oxygen double bond. ${ }^{3,7}$ Consequently, the researchers have focused on reducing the onset potential (reducing the overpotential) of the ORR to increase the efficiency of the PEMFC. ${ }^{8,9}$ The ORR has proven to be troublesome as it can occur via a two- or four-electron pathway, depending upon the effectiveness of the electrocatalyst implemented, with the four-electron pathway being

Received: April 12, 2017

Accepted: June 2, 2017

Published: June 2, 2017 


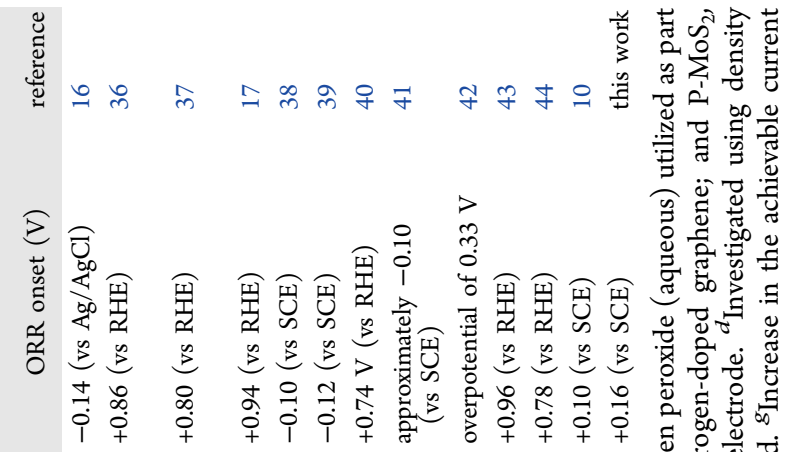

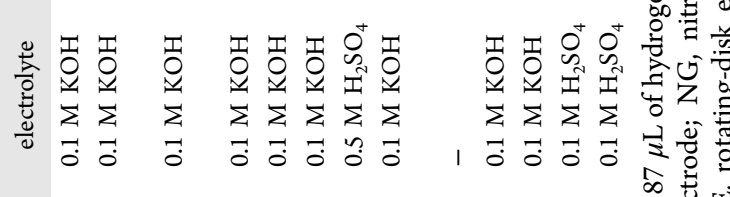

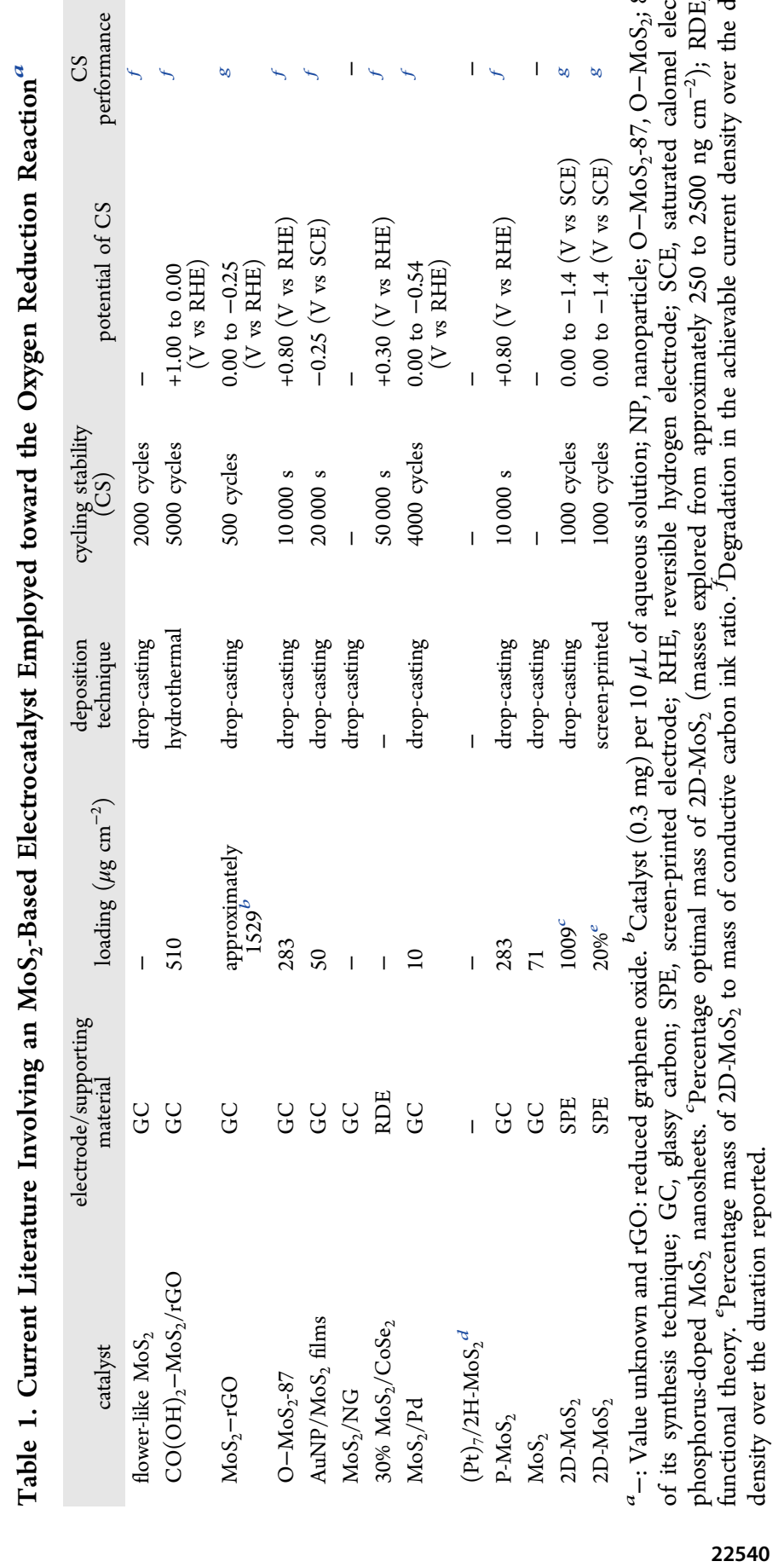


desirable as the reaction product is water, ${ }^{10} \mathrm{O}_{2}+2 \mathrm{H}^{+}+2 \mathrm{e}^{-} \rightarrow$ $\mathrm{H}_{2} \mathrm{O}_{2}+2 \mathrm{H}^{+}+2 \mathrm{e}^{-} \rightarrow 2 \mathrm{H}_{2} \mathrm{O}$. An ineffective electrocatalyst will result in the ORR occurring by a two-electron pathway, ${ }^{16-18,21}$ leading to the production of $\mathrm{H}_{2} \mathrm{O}_{2}$ that can cause the degradation of the proton exchange membrane and a fouling effect upon the anode and the cathode. This will result in the PEMFC having a severe decline in its achievable voltage. ${ }^{10}$ Literature suggests that there are direct ${ }^{11}$ and indirect ${ }^{12} \mathrm{H}_{2} \mathrm{O}_{2}$ poisoning mechanisms. Platinum $(\mathrm{Pt})$ is the ideal electrocatalyst for the ORR as it allows for the reaction pathway to occur via a four-electron route, producing favorably water as the end product. ${ }^{4}$ However, the inherent problems of utilizing Pt, such as its high cost, have limited the cost effectiveness of the PEMFC and thus have reduced their desirability as alternatives to FF-based technologies. The two-dimensional (2D) nanomaterials have been the focus of research for the search of alternative ORR electrocatalysts. ${ }^{13-15}$

$2 \mathrm{D}$ molybdenum disulfide $\left(2 \mathrm{D}-\mathrm{MoS}_{2}\right)$ is an ORR electrocatalytic material. ${ }^{16}$ A typical $2 \mathrm{D}-\mathrm{MoS}_{2}$ nanosheet is composed of basal and edge planes, and it has been reported that the edge planes are considered to be the site of electrocatalytic activity for the ORR. ${ }^{16,17}$ In particular, it is the electropositive molybdenum atoms, at the edge sites, that bind the electronegative oxygen atoms and exhibit the electrocatalytic behavior toward the ORR. ${ }^{17}$ Table 1 represents a thorough overview of the literature reporting $\mathrm{MoS}_{2}$-based electrode materials explored toward the ORR. From the inspection of Table 1, repeated use of the drop-casting technique as a method of modifying the supporting electrode, typically a glassy carbon electrode, can be observed. We define the drop-casting technique as the process of dispersing an electrocatalytic material into a suitable media/solvent from which aliquots are then taken and pipetted onto the chosen electrode surface. This solvent evaporates leaving behind the electrocatalytic material immobilzed upon the electrode surface that allows "electrical wiring" of the electrocatalytic material. Drop-casting is a convenient and simple technique to explore the electrocatalytic properties of a $2 \mathrm{D}$ nanomaterial. It does, however, have numerous disadvantages, such as poor stability, low reproducibility, lack of scalability for industrial applications, and uncontrollable distribution of the material deposited; this is especially a problem when using $2 \mathrm{D}$ materials that display differing heterogeneous electrode transfer kinetics in their monolayer, quasi, and bulk forms. ${ }^{18}$ This work, therefore, seeks to produce a facile methodology to modify an electrode with a 2D material that does not display the negatives of drop-casting. Additionally, there is an issue of how one can translate the identified electrocatalytic material from the laboratory into industry, such as electrodes in PEMFCs.

To overcome the critical issues identified above, we report the design, fabrication, and evaluation of inks that incorporate $2 \mathrm{D}-\mathrm{MoS}_{2}$ that are able to be screen-printed producing 2D$\mathrm{MoS}_{2}$ screen-printed electrodes (2D-MoS - SPEs). These inks and $2 \mathrm{D}-\mathrm{MoS}_{2}$-SPEs are shown to be electrocatalytic toward the ORR. The 2D-MoS 2 -SPEs have the advantages of tailorability, where different amounts and lateral sizes of the $2 \mathrm{D}$ materials can be incorporated, which change the electrochemical performance and critically have scales of economy as a result of their ability to be produced in large volumes and provide a route for the mass production of electrocatalytic surfaces that have the potential to be utilized in fuel cells. Future studies could seek to incorporate any of the plethora of the $2 \mathrm{D}$ nanomaterials into inks to produce SPEs designed to meet a niche in electrochemical applications.

\section{EXPERIMENTAL SECTION}

2.1. Chemicals. The chemicals utilized, herein, were all of the analytical grade and were utilized as received from Sigma-Aldrich without any further purification; this includes the $\mathrm{MoS}_{2}$ powders utilized in the production of the $2 \mathrm{D}-\mathrm{MoS}_{2}$-SPEs. Three variants of the $2 \mathrm{D}-\mathrm{MoS}_{2}$ powder were implemented, each having a distinct flake lateral width, reported independently by Sigma-Aldrich: $90 \mathrm{~nm},{ }^{19}<2$ $\mu \mathrm{m},{ }^{20}$ and approximately $6 \mu \mathrm{m} .^{21}$ Sigma-Aldrich reports the average lateral width of the $2 \mathrm{D}-\mathrm{MoS}_{2}$ particles in powder but details are lacking about the characterization performed to justify these numbers. We observe that the $90 \mathrm{~nm} 2 \mathrm{D}-\mathrm{MoS}_{2}$, when suspended into a solvent and subsequently redispersed to allow characterization to be performed, agglomerates to form larger particles with an average lateral width of approximately $400 \mathrm{~nm}$ (see Figure 1). This increase in the lateral width

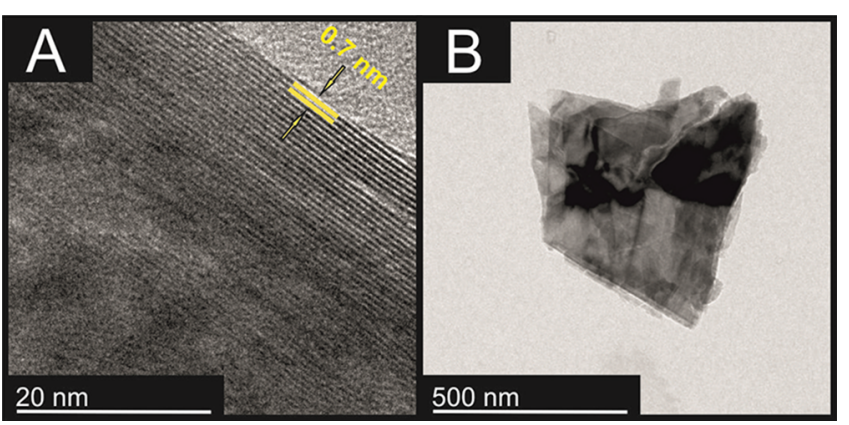

Figure 1. TEM images of the commercially sourced $400 \mathrm{~nm} 2 \mathrm{D}-\mathrm{MoS}_{2}$. (A) Scale bar: $20 \mathrm{~nm}$ and (B) scale bar: $500 \mathrm{~nm}$.

as a result of agglomeration was not observed for the $2 \mathrm{D}-\mathrm{MoS}_{2}$ particles with lateral widths of $<2 \mu \mathrm{m}^{20}$ and approximately $6 \mu \mathrm{m} .{ }^{21} \mathrm{We}$, therefore, use the notations $400 \mathrm{~nm}, 2$, and $6 \mu \mathrm{m}$ when differentiating between the $\mathrm{MoS}_{2}$ particles utilized within this study.

2.2. Electrochemical Measurements. Deionized water (resistivity $<18.2 \mathrm{M} \Omega \mathrm{cm}$ ) was utilized to produce all aqueous solutions. All ORR measurements were recorded in $0.1 \mathrm{M} \mathrm{H}_{2} \mathrm{SO}_{4}$; the sulfuric acid solution utilized was of the highest possible grade available from Sigma-Aldrich (99.999\%, double distilled for trace metal analysis). The $0.1 \mathrm{M}$ sulfuric acid solution utilized for the ORR tests contained a 0.9 $\mathrm{mM}$ concentration of oxygen; this concentration was achieved by $100 \%$ oxygen being bubbled through the solution for $1 h^{22,23}$ Note, when the authors of this article denote the ORR onset, it is taken as the potential when there is a $25 \mu \mathrm{A} \mathrm{cm} \mathrm{cm}^{-2}$ deviation from the background current. ${ }^{10}$

An Ivium CompactStat (Netherlands) potentiostat was utilized to make all of the electrochemical measurements. The electrochemical measurements were carried out with an SPE, $\mathrm{Pt}$, and saturated calomel electrode (SCE) as the working, counter, and reference electrodes, respectively. The SPEs were fabricated via screen-printing the appropriate ink through a stencil comprising the design of the electrode/configuration using a DEK 248 screen-printing machine (DEK, Weymouth, U.K.) onto a polyester (Autostat, $250 \mu \mathrm{m}$ thickness) flexible film. This layer is then cured using a fan oven at $60{ }^{\circ} \mathrm{C}$ for $30 \mathrm{~min}$. A dielectric paste (product code D2070423D5; Gwent Electronic Materials Ltd., U.K.) is then utilized to insulate the working electrode area of the printed design from its electrical connection. After curing at $60{ }^{\circ} \mathrm{C}$ for $30 \mathrm{~min}$, the SPEs/surfaces were ready to be used. For comparative purposes, a platinum electrode (1.6 $\mathrm{mm}, \mathrm{BAS}, \mathrm{USA}$ ) was tested as a working electrode toward the ORR and hydrogen evolution reaction (HER) under the same conditions as that of the fabricated $2 \mathrm{D}-\mathrm{MoS}_{2}$-SPEs and graphite SPEs (G-SPEs).

2.3. 2D-MoS $\mathrm{S}_{2}$-SPE Production. Figure $\mathrm{S} 1$ shows the range of designs and geometries that can be achieved via screen-printing, ranging from microbands ( 50 micron width by $2 \mathrm{~cm}$ length), as shown 
in Figure S1A, through to macroelectrodes, such as the SPE shown within Figure S1D, which has a working area of $4.5 \mathrm{~cm}^{2}$. Finally, the design that was utilized in this study is shown in Figure S1C, which has a diameter and a working area of $3 \mathrm{~mm}$ and $0.0707 \mathrm{~cm}^{2}$, respectively. We demonstrate this range of SPE designs to highlight the versatility of the electrode design inherent with the screen-printing technology. ${ }^{18}$ Figure 2 overviews the fabrication steps required to fabricate the 2D$\mathrm{MoS}_{2}$-SPEs.

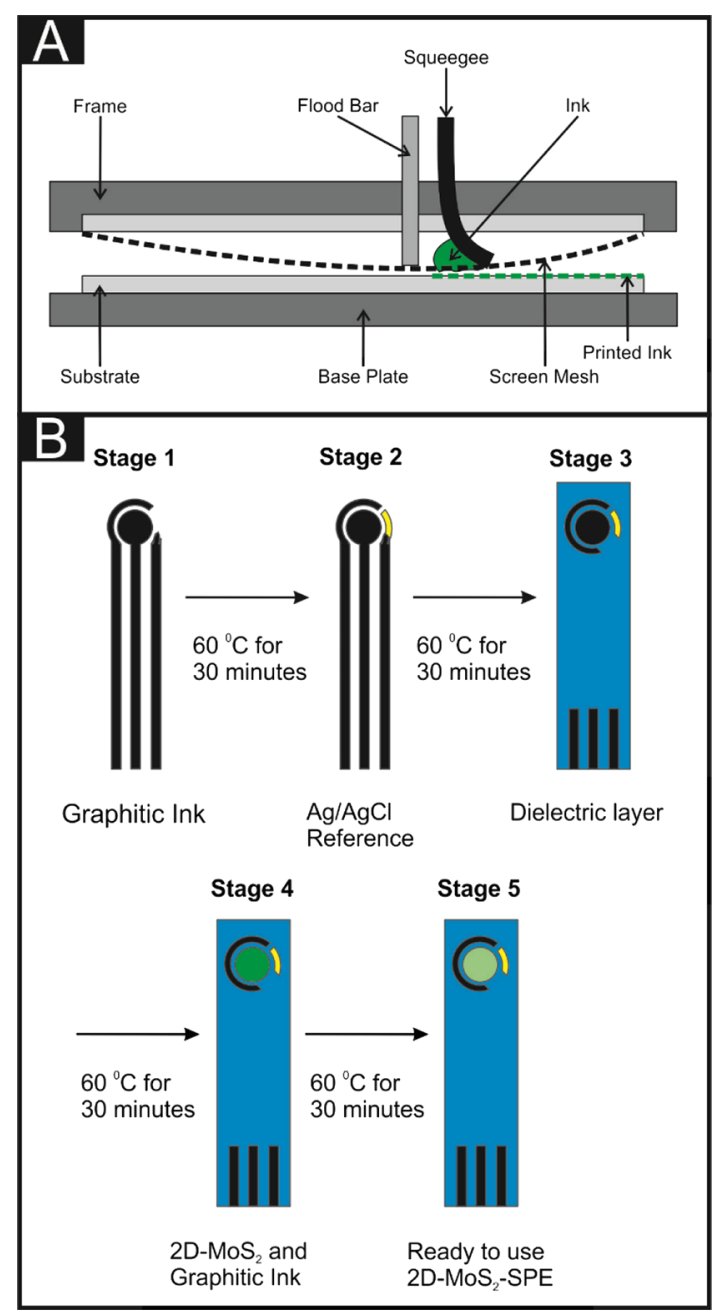

Figure 2. Illustration of the (A) screen-printing process employed in this paper and (B) the individual stages necessary to fabricate the mass-producible $2 \mathrm{D}-\mathrm{MoS}_{2}$-SPEs.

A $2 \mathrm{D}-\mathrm{MoS}_{2}$ ink, made from first principles, was considered using a range of solvents, binders, and graphitic materials. A range of inks were formulated using a combination of fast and slow drying solvents along with just solely $2 \mathrm{D}-\mathrm{MoS}_{2}$ (the variants reported earlier) and a range of polymeric binders. Other ink formulations that have additional supporting carbon black/graphite materials and the $2 \mathrm{D}-\mathrm{MoS}_{2}$ variants were also explored. In all endeavors, we found that inks were produced and were able to be screen-printed but had poor/nonexistent electrochemical responses in terms of the ORR overpotential $(>-0.9 \mathrm{~V}$ vs SCE). Tailoring/optimizing the component of ink formulation did not result in any improvements in the performances, and additionally, the screen-printing process resulted in only a few print cycles being possible before the drying of the screen and becoming unusable. Consequently, this avenue of research was discontinued. To overcome the problems identified above, it was therefore decided to utilize a preexisting commercial graphitic ink. This has the advantage that the commercial ink allows the mass production of $2 \mathrm{D}-\mathrm{MoS}_{2}$ electrode that can be printed for many print cycles without screen-blocking but yet provide advantageous electrochemical performance. Thus, it was decided to incorporate the 2D$\mathrm{MoS}_{2}$ variants into an existing carbon-graphite ink formulation (product code C2000802P2; Gwent Electronic Materials Ltd., U.K.). The $2 \mathrm{D}-\mathrm{MoS}_{2}$ was incorporated into the bulk of the graphite ink on the basis of the weight percent of $M_{\mathrm{P}}$ and $M_{\mathrm{J}}$, where $M_{\mathrm{P}}$ is the mass of particulate, in this case, the $2 \mathrm{D}-\mathrm{MoS}_{2}$, and $M_{\mathrm{I}}$ is the mass of the ink formulation used in the printing process, that is, $\%=\left(M_{\mathrm{P}} / M_{\mathrm{I}}\right) \times 100$. The weight percent of $M_{\mathrm{P}}$ and $M_{\mathrm{I}}$ varied over the range of $0-40 \%$. The maximum amount of $2 \mathrm{D}-\mathrm{MoS}_{2}$ that can be incorporated into the carbon-graphite ink was found to correspond to $40 \%$ as any further percentage of incorporation increases the viscosity of the resultant ink to such an extent, where it is not screen-printable via the technique utilized herein. It is possible to make an estimate as to the mass loading of each $2 \mathrm{D}-\mathrm{MoS}_{2}$-SPE with regard to weight. Through making a weight measurement pre and post Stage 4 of the screen-printing process, as illustrated in Figure 2, it is possible to ascertain the weight of the $2 \mathrm{D}-\mathrm{MoS}_{2}$-modified ink on the surface of each electrode. We then prescribe a percentage of this weight to the $2 \mathrm{D}-\mathrm{MoS}_{2}$. Utilizing this method, we deduced a value of 101.4, 202.7, 405.5, and $810.9 \mu \mathrm{g}$ for the mass loading of $2 \mathrm{D}-\mathrm{MoS}_{2}$ in a 5, 10, 20, and 40\% 2D-MoS $2_{2}^{-}$ SPEs. Owing to the nature of the screen-printing process, it is only possible to ascertain roughly accurate mass of $2 \mathrm{D}-\mathrm{MoS}_{2}$ within the ink of each working electrode; we, therefore, use a percentage denotation throughout. Note that the thickness of screen-printed film/electrode depends upon the viscosity of the ink, the screen, and various printing parameters. In our case, the thickness of the print is in the range of 12-15 microns and is hence termed "thick film" technology (historically). The advantage of screen-printing is that reproducible films result on a mass-producible scale. When the electrocatalyst is added to the ink, that is, adding a nanomaterial to micromaterial, the print variation is unsurprisingly unaffected.

To reduce the amount of $2 \mathrm{D}-\mathrm{MoS}_{2}$ material utilized in the fabrication of the $2 \mathrm{D}-\mathrm{MoS}_{2}$-SPEs, this resulting mixture was screenprinted on top of an initial screen-printed carbon-graphite surface that has been screen-printed using only the carbon-graphite ink formulation (see earlier). Following the screen-printing of the 2D$\mathrm{MoS}_{2}$-modified ink, a curing step is required. A variety of temperatures and curing times were considered before an optimized time period and temperature of $30 \mathrm{~min}$ at $60{ }^{\circ} \mathrm{C}$ were implemented; prior curing times and temperatures resulted in poor electrochemical performances. The $2 \mathrm{D}-\mathrm{MoS}_{2}$ was screen-printed on top of the carbon-graphite surface but with only the working electrode area being printed upon and then cured as described earlier $\left(60{ }^{\circ} \mathrm{C}\right.$ for $\left.30 \mathrm{~min}\right)$. This is to save the amount of $2 \mathrm{D}-\mathrm{MoS}_{2}$ required and to reduce the overall cost of the electrodes. A visual description of the overall 2D-MoS 2 -SPE screenprinting process used to fabricate the $2 \mathrm{D}-\mathrm{MoS}_{2}$-SPEs is presented in Figure 2.

\section{RESULTS AND DISCUSSION}

3.1. Characterization of the 2D-MoS ${ }_{2}$ Utilized in the Fabrication of the 2D-MoS ${ }_{2}$-SPEs. Independent physicochemical characterization was performed on the commercially sourced $2 \mathrm{D}-\mathrm{MoS}_{2}$ powders utilized to produce the $2 \mathrm{D}-\mathrm{MoS}_{2}-$ SPEs. ${ }^{19-21}$ Figure 1 depicts typical transmission electron microscopy (TEM) images of the $2 \mathrm{D}-\mathrm{MoS}_{2}$ that was reported to have a $90 \mathrm{~nm}$ lateral width in its powder form by SigmaAldrich. ${ }^{19}$ It is clear that the lateral width of the $\mathrm{MoS}_{2}$ nanosheets is approximately $400 \mathrm{~nm}$ with an internanosheet spacing of approximately $0.7 \mathrm{~nm}$, which agrees with the literature. ${ }^{24}$ Figure $1 \mathrm{~B}$ indicates that there is some aggregation of the nanosheets that is the case for all nanosheet materials after dispersion from their supporting solvents onto a platform, where it is possible to image them using TEM. This agglomeration explains the increase in the lateral width of the observed flakes from the sizes reported by Sigma-Aldrich. 

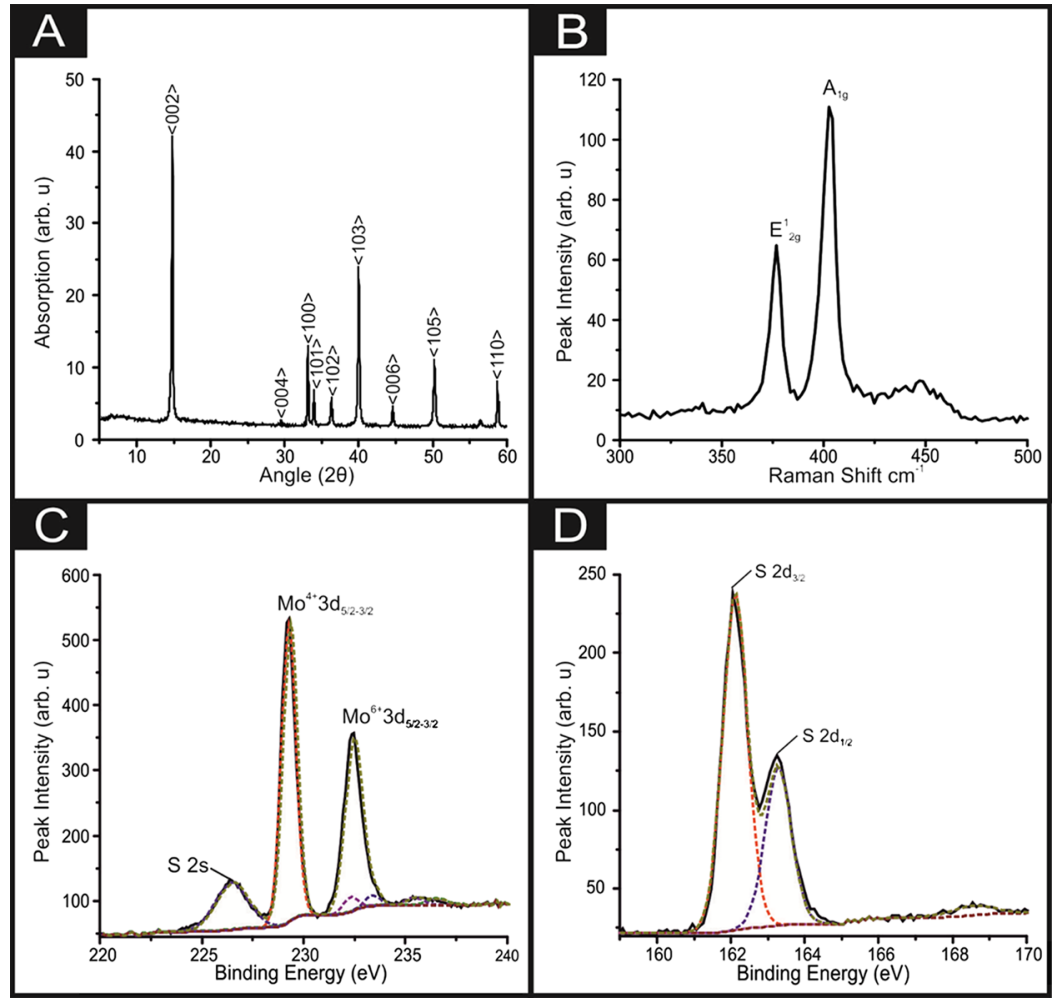

Figure 3. Characterization of the commercially sourced $400 \mathrm{~nm} 2 \mathrm{D}-\mathrm{MoS}_{2}$, which is the basis of the fabricated 2D-MoS $\mathrm{S}_{2}-\mathrm{SPEs} \mathrm{s}_{400 \mathrm{~nm}}$; (A) XRD spectra of $2 \mathrm{D}-\mathrm{MoS}_{2}$ and (B) Raman spectra of 2D-MoS . High-resolution XPS spectra of Mo 3d and S 2d regions of $\mathrm{MoS}_{2}$ (C and D).

\section{A}

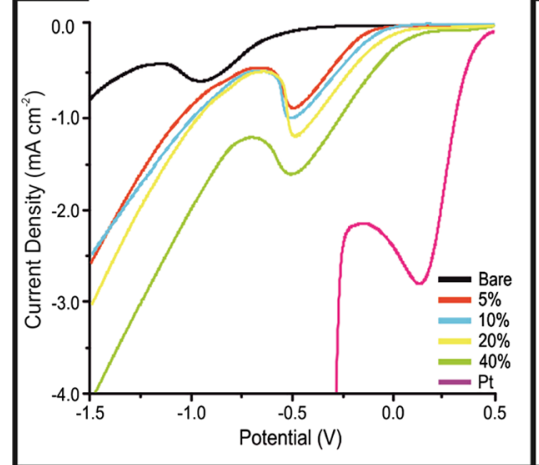

$\mathrm{B}$
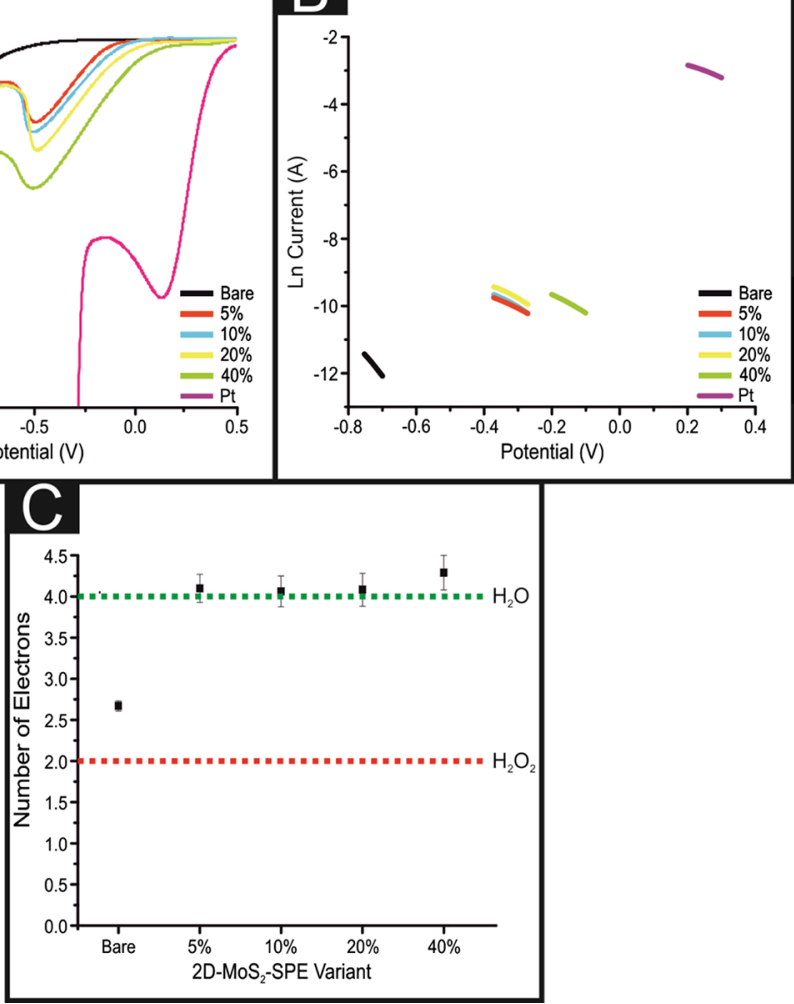

Figure 4. (A) LSV of G-SPE and 5, 10, 20, and 40\% 2D-MoS ${ }_{2}-\mathrm{SPEs}_{400 \mathrm{~nm}}$ showing the onset and peak potential for the ORR. Scan rate utilized: 0.025 $\mathrm{V} \mathrm{s}^{-1}$ (vs SCE). Solution composition utilized: $0.1 \mathrm{M} \mathrm{H}_{2} \mathrm{SO}_{4}$. (B) Tafel analysis; ln of current density vs potential Faradaic section of the LSV viewable in (A). (C) The number of electrons involved in the ORR mechanism for a (bare) G-SPE and 5, 10, 20, and 40\% 2D-MoS ${ }_{2}$-SPEs $400 \mathrm{~nm}$ (average standard deviation of three replicates). The green and red dotted lines show the number of electrons required for the ORR process to proceed via the desirable mechanism to produce $\mathrm{H}_{2} \mathrm{O}(n=4)$ or the undesirable mechanism to $\mathrm{H}_{2} \mathrm{O}_{2}(n=2)$, respectively. 
The X-ray diffraction (XRD) analysis performed of the 2D$\mathrm{MoS}_{2}$ is presented in Figure 3A. Major diffraction peaks that are characteristic of hexagonal $\mathrm{MoS}_{2}$, observed within the literature, are visible at $2 \theta=14.7^{\circ}, 29.4^{\circ}, 33.1^{\circ}, 33.9^{\circ}, 36.3^{\circ}, 40.0^{\circ}, 44.6^{\circ}$, $50.2^{\circ}$, and $58.8^{\circ}$ corresponding to the planes of (002), (004), (100), (101), (102), (103), (006), (105), and (110), respectively. ${ }^{25,26}$ Then, Raman analysis was performed (Figure $3 B$ ), where the $E_{2 g}^{1}$ and $A_{1 g}$ vibrational bands and vibrational peaks are clearly visible at 376.8 and $402.5 \mathrm{~cm}^{-1}$, respectively, giving a peak $\left(\mathrm{E}_{2 \mathrm{~g}}^{1}-\mathrm{A}_{1 \mathrm{~g}}\right)$ distance of $25.7 \mathrm{~cm}^{-1}$, which is more sensitive to $\mathrm{MoS}_{2}$ thickness than the individual Raman vibrational band frequency. The $\mathrm{E}_{2 \mathrm{~g}}^{1}-\mathrm{A}_{1 \mathrm{~g}}$ distance corresponds to the literature value expected for bulk $\mathrm{MoS}_{2}$ (<6 $\mathrm{MoS}_{2}$ nanosheet layers). ${ }^{27-29}$ Last, X-ray photoelectron spectroscopy (XPS) analysis was performed to determine the elemental composition of the $2 \mathrm{D}-\mathrm{MoS}_{2}$ powder utilized herein with Figure 3C,D showing high-resolution spectra of the Mo $3 \mathrm{~d}$ and $S 2 p$ regions of $2 \mathrm{D}-\mathrm{MoS}_{2}$. Table $\mathrm{S} 1$ indicates that the Mo and S were present at the expected ratio $(8.43 \%$ Mo atomic concentration to $20.11 \% \mathrm{~S}$ atomic concentration that gives a ratio of 1:2.4, respectively). Note that $\mathrm{MoS}_{2}$ flakes with lateral widths of approximately 2 and $6 \mu \mathrm{m}$ were also used in the fabrication of $2 \mathrm{D}-\mathrm{MoS}_{2}$-SPEs with their physicochemical characterization being presented in Figures S2 and S3, respectively. Utilizing the $2 \mathrm{D}-\mathrm{MoS}_{2}$ flakes with different lateral widths (approximately $400 \mathrm{~nm}, 2$, and $6 \mu \mathrm{m}$ ) allows us to investigate the effect of altering the active edge to relatively inert basal site ratio upon the ability of the $2 \mathrm{D}-\mathrm{MoS}_{2}$-SPEs to catalyze the ORR, as the flakes with small lateral widths will have a larger edge to basal site ratio than the flakes with larger lateral widths.

Given the results of the physicochemical analysis performed on the commercially sourced $2 \mathrm{D}-\mathrm{MoS}_{2}$ powder, which was utilized in this study to produce the electrocatalytic inks, it is evident that it comprises high-quality $2 \mathrm{D}-\mathrm{MoS}_{2}$ nanosheets.

3.2. Evaluation of the 2D-MoS 2 -SPEs toward the ORR. The $400 \mathrm{~nm}$ 2D-MoS 2 -SPEs (2D-MoS $\left.-\mathrm{SPE}_{400 \mathrm{~nm}}\right)$ were fabricated as described in the Experimental Section using the $2 \mathrm{D}-\mathrm{MoS}_{2}$ powder characterized above. Note that the interaction between the graphite ink and the $2 \mathrm{D}-\mathrm{MoS}_{2}$ is one of only physical blending. This is confirmed using XPS on the surface of a $40 \% 2 \mathrm{D}-\mathrm{MoS}_{2}$-SPE, which demonstrates the same spectra as that of the $2 \mathrm{D}-\mathrm{MoS}_{2}$ powder as described in Results and Discussion (see Figure S4A,B). Details of TEM, SEM, and XPS used in this study are given in the Supporting Information. Previous studies have shown that $2 \mathrm{D}-\mathrm{MoS}_{2}$ is electrocatalytic toward the HER; ${ }^{28}$ it was therefore essential to benchmark the $2 \mathrm{D}-\mathrm{MoS}_{2}-\mathrm{SPE}_{400 \mathrm{~nm}}$ in $0.5 \mathrm{M} \mathrm{H}_{2} \mathrm{SO}_{4}$. This ensures that no electrochemical activity in the ORR region of the linear sweep voltammogram (LSV) would convolute the signal output of $2 \mathrm{D}-\mathrm{MoS}_{2}-\mathrm{SPE}_{400 \mathrm{~nm}}$; these results are described fully in Figure S5.

Figure 4A shows a characteristic LSV obtained using a GSPE; 5, 10, 20, and 40\% 2D-MoS $-\mathrm{SPE}_{400 \mathrm{~nm}}$; and, for comparative purposes, a Pt electrode in oxygenated $0.5 \mathrm{M}$ $\mathrm{H}_{2} \mathrm{SO}_{4}$ (see Experimental Section). ${ }^{10}$ Upon inspection of this figure, it is clear that the (bare) G-SPE displayed an ORR onset potential, more electronegative than the other electrodes examined, and a smallest peak current of approximately $-0.53 \mathrm{~V}$ and $-635 \mu \mathrm{A} \mathrm{\textrm {cm } ^ { - 2 }}$, respectively. The Pt electrode displays the optimal ORR onset potential and the largest peak current of $+0.46 \mathrm{~V}$ and $2.92 \mathrm{~mA} \mathrm{~cm}{ }^{-2}$, respectively. The $2 \mathrm{D}$ $\mathrm{MoS}_{2}-\mathrm{SPE}_{400 \mathrm{~nm}}$ displays a significantly less electronegative onset potential and an increase in the peak ORR current compared with that of the G-SPE; however, all of the 2D$\mathrm{MoS}_{2}-\mathrm{SPE}_{400 \mathrm{~nm}}$ have a more electronegative and smaller peak current compared with that of the Pt electrode. It is clearly observed that as the percentage mass incorporation of $2 \mathrm{D}$ $\mathrm{MoS}_{2}$ into the $2 \mathrm{D}-\mathrm{MoS}_{2}-\mathrm{SPE}_{400 \mathrm{~nm}}$ increases, there is a decrease in the electronegativity and an increase in the current density, with the ORR onset and peak potential varying from approximately -0.19 to $+0.16 \mathrm{~V}$ and approximately -0.89 to $-1.62 \mathrm{~mA} \mathrm{~cm}{ }^{-2}$ for a $5-40 \%$ incorporation of $2 \mathrm{D}-\mathrm{MoS}_{2}$ into $2 \mathrm{D}-\mathrm{MoS}_{2}-\mathrm{SPE}_{400 \mathrm{~nm}}$, respectively. This effect is likely attributed to the $40 \% 2 \mathrm{D}-\mathrm{MoS}_{2}-\mathrm{SPE}_{400 \mathrm{~nm}}$ having the largest mass of $2 \mathrm{D}$ $\mathrm{MoS}_{2}$ present, which results in it having the largest number of exposed edge sites on the electrode surfaces, making it evident that as the mass incorporation of $2 \mathrm{D}-\mathrm{MoS}_{2}$ increases, the ORR onset becomes less electronegative and the peak potential increases.

It was shown that the electrochemical responses obtained for the $2 \mathrm{D}-\mathrm{MoS}_{2}-\mathrm{SPE}_{400 \mathrm{~nm}}$ were a result of diffusional processes and were not convoluted by the presence of a thin-layer effect. This was shown by a comparison between the log scan rate $(v)$ and log peak current of the reduction redox peak ( $\left.I_{\mathrm{p}}^{\text {Irrev }}\right)$ giving a linear trend value no larger than 0.52 (see Table S2 for detailed values).

Then, the number of electrons involved in the ORR reaction mechanism was explored for the $2 \mathrm{D}-\mathrm{MoS}_{2}-\mathrm{SPE}_{400 \mathrm{~nm}}{ }^{13}$ There is no rotating-disk electrode methodology for determining the number of electrons involved in the ORR that are compatible with the SPEs developed in this study; Tafel analysis was therefore utilized as a method to determine the number of electrons involved in the ORR electrochemical mechanism. ${ }^{30}$ First, a plot of $\ln (I)$ versus $E_{\mathrm{p}}(\mathrm{V})$ was produced for the G-SPE and the four $2 \mathrm{D}-\mathrm{MoS}_{2}-\mathrm{SPE}_{400 \mathrm{~nm}}$ variants (see Figure $4 \mathrm{~B}$ and Table S2). The information required to do this was taken from the ORR LSVs (which were utilized to produce Figure 4A) and using the following equation $30 \frac{\delta \ln I}{\delta E}=\frac{\left(\alpha n^{\prime}\right) F}{R T}$. The slope of the plot of $\ln (I)$ versus $E_{\mathrm{p}}(\mathrm{V})$ corresponds to $\delta \ln I / \delta E_{\mathrm{p}}$, where $\alpha$ signifies the electron-transfer coefficient, $F$ signifies the Faraday constant, $n^{\prime}$ signifies the number of electrons transferred in the rate-determining step, $R$ signifies the universal gas constant, and $T$ signifies the solution temperature $(\mathrm{K})$. The first electron transfer is electrochemically irreversible, and therefore, the $n^{\prime}$ utilized is $1 .^{31}$ The $\alpha n^{\prime}$ values for each electrode were unique and calculated separately from the Tafel equation above. By incorporating these values into the Randles-Ševcik equation (shown below), it was possible to deduce the number of electrons involved in the reaction mechanism $(n)^{32}$

$$
I_{\mathrm{p}}^{\text {Irrev }}= \pm 0.496\left(\alpha n^{\prime}\right)^{1 / 2} n F A C(F D v / R T)^{1 / 2}
$$

where $C$ is concentration that is assumed for the oxygensaturated solution $(0.9 \mathrm{mM}),{ }^{33}$ a literature diffusion coefficient (D) value of $2.0 \times 10^{-5} \mathrm{~cm}^{2} \mathrm{~s}^{-1}$ is assumed, ${ }^{23,34} A$ is the area of the electrode, and $v$ is the voltammetric scan rate $\left(\mathrm{V} \mathrm{s}^{-1}\right)$. Figure 4C depicts the $n$ value of the ORR mechanism for the G-SPE and all $2 \mathrm{D}-\mathrm{MoS}_{2}-\mathrm{SPE}_{400 \mathrm{~nm}}$ variants. The results above show that for G-SPEs, $n=2.67$, which suggests that the major product is $\mathrm{H}_{2} \mathrm{O}_{2}$, as is suggested independently for a carbonbased electrode within the literature. ${ }^{31}$ On the other hand, the $5,10,20$, and $40 \% 2 \mathrm{D}-\mathrm{MoS}_{2}-\mathrm{SPE}_{400 \mathrm{~nm}}$ exhibit an average $(\mathrm{N}=$ 3 ) $n$ of approximately $4.10,4.06,4.08$, and 4.29 , respectively, which suggests that the major product of the ORR reaction mechanism is the preferential $\mathrm{H}_{2} \mathrm{O}$. Studies by Suresh et al. ${ }^{16}$ 


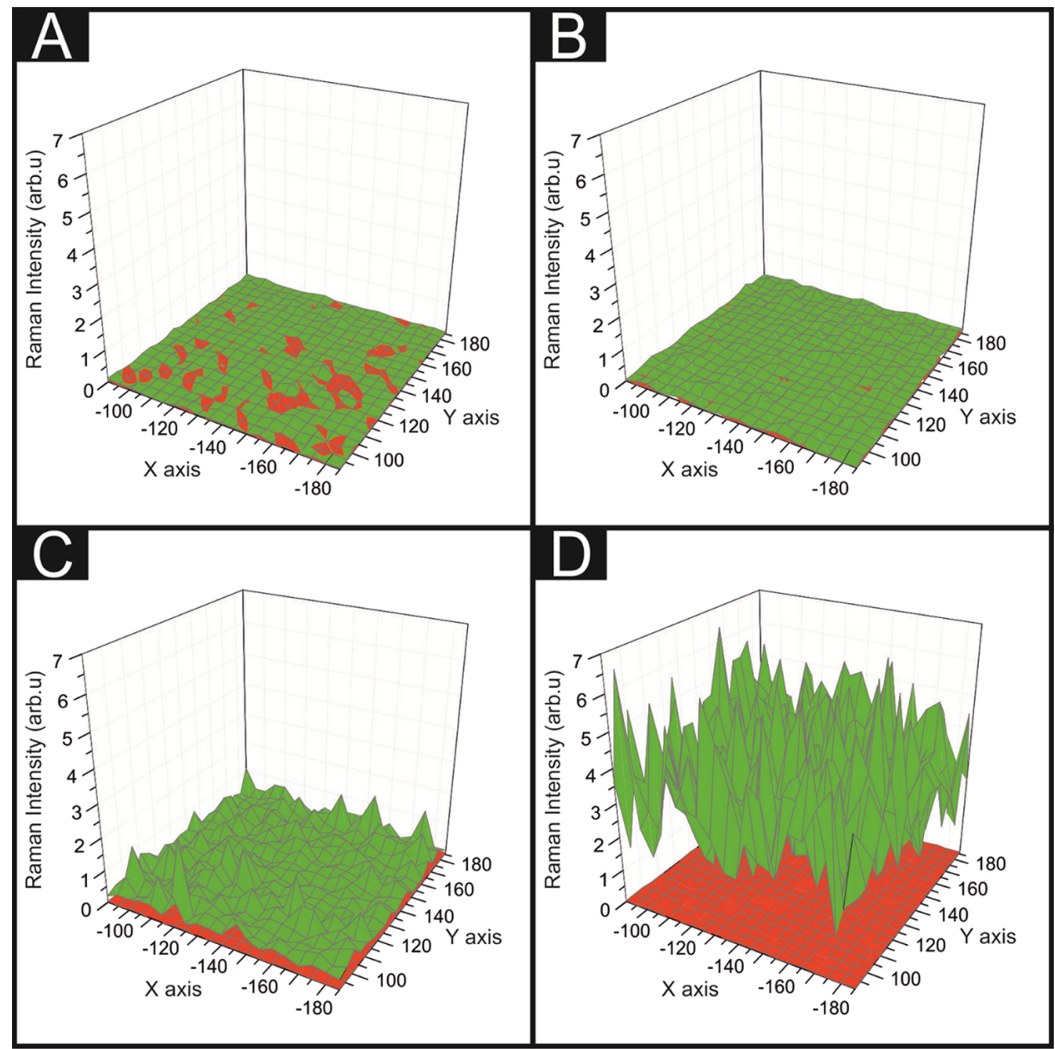

Figure 5. Raman maps of (A) $5 \% 2 \mathrm{D}-\mathrm{MoS}_{2}-\mathrm{SPE}_{400 \mathrm{~nm}}$, (B) $10 \% 2 \mathrm{D}-\mathrm{MoS}_{2}-\mathrm{SPE}_{400 \mathrm{~nm}}$, (C) $20 \% 2 \mathrm{D}-\mathrm{MoS}_{2}-\mathrm{SPE}_{400 \mathrm{~nm}}$, and (D) $40 \% 2 \mathrm{D}-\mathrm{MoS}_{2}-\mathrm{SPE}_{400 \mathrm{~nm}}$. Quadrat intersects representing a ratio between the $\mathrm{MoS}_{2}$ characteristic vibrational band at $380 \mathrm{~cm}^{-1}$ and the graphitic vibrational band at 1580 $\mathrm{cm}^{-1}$. The green map is the $2 \mathrm{D}-\mathrm{MoS}_{2}-\mathrm{SPE}$ and the underlying red represents a bare graphitic electrode surface.

(alkaline conditions) and Rowley-Neale et al. ${ }^{10}$ (acidic conditions) have previously produced an ORR mechanism involving four electrons; however, both of these studies utilized the drop-casting technique and showed a decrease in the achievable current over the course of a cycling stability (CS) test; we believe that we are the first to produce a screenprintable electrocatalytic $2 \mathrm{D}-\mathrm{MoS}_{2}$-incorporated electrode that are observed to exhibit an ORR mechanism that occurs via the desirable four-electron pathway producing $\mathrm{H}_{2} \mathrm{O}$.

3.3. Exploring the Effect of $\mathrm{MoS}_{2}$ Flake Size upon the ORR Activity of $\mathrm{MoS}_{2}$-SPEs: Optimization of the Electrocatalytic Performance toward the ORR. An important consideration was the effect of $\mathrm{MoS}_{2}$ particle size upon the ability of $2 \mathrm{D}-\mathrm{MoS}_{2}$-SPEs to catalyze the ORR. We, therefore, fabricated $2 \mathrm{D}-\mathrm{MoS}_{2}-\mathrm{SPEs}_{2 \mu \mathrm{m}}$ and $2 \mathrm{D}-\mathrm{MoS}_{2}-\mathrm{SPEs}_{6 \mu \mathrm{m}}$ variants to explore their ability to catalyze the ORR, the results of which are shown in Figures S6 and S7. 2D-MoS $-\mathrm{SPEs}_{2 \mu \mathrm{m}}$ displayed an ORR onset potential for its optimal mass modification (40\%) of approximately $-0.07 \mathrm{~V}$ (see Figure S6A), which is less electronegative than the ORR onset displayed by the $40 \%$ $2 \mathrm{D}-\mathrm{MoS}_{2}-\mathrm{SPEs}_{6 \mu \mathrm{m}}$ (see Figure S7A). The ORR onset potentials for the 2D-MoS $2-\mathrm{SPEs}_{2 \mu \mathrm{m}}$ and 2D-MoS $-\mathrm{SPEs}_{6 \mu \mathrm{m}}$ were both more electronegative than that displayed by the $2 \mathrm{D}-\mathrm{MoS}_{2}-$ $\mathrm{SPEs}_{400 \mathrm{~m}}$. With regard to the number of electrons involved in the ORR reaction mechanism, neither $2 \mathrm{D}-\mathrm{MoS}_{2}-\mathrm{SPEs}_{2 \mu \mathrm{m}}$ nor $2 \mathrm{D}-\mathrm{MoS}_{2}-\mathrm{SPEs}_{6 \mu \mathrm{m}}$ allowed for the desirable four-electron pathway at any percentage mass of incorporation (see Figures S6C and S7C). It is clearly evident that implementing a smaller particle size of $\mathrm{MoS}_{2}$ produces $\mathrm{MoS}_{2}$-SPEs results in a more beneficial ORR activity. The observed change in ORR performance is a clear result of the differing morphologies of the $2 \mathrm{D}-\mathrm{MoS}_{2}$ used in the fabrication of the SPEs, where it appears that the smaller flakes have a greater proportion of active edge sites than that of an equivalent mass of larger flakes.

To explore the charge transfer resistance inherent by each $2 \mathrm{D}-\mathrm{MoS}_{2}-\mathrm{SPE}_{400 \mathrm{~nm}}$ an electrochemical impedance spectroscopy (EIS) study was also carried out. It determined that the incorporation of $2 \mathrm{D}-\mathrm{MoS}_{2}$ into $2 \mathrm{D}-\mathrm{MoS}_{2}-\mathrm{SPE}_{400 \mathrm{~nm}}$ was observed to lower the charge transfer resistance $(\Omega)$ with the $40 \% 2 \mathrm{D}-\mathrm{MoS}_{2}-\mathrm{SPE}_{400 \mathrm{~nm}}$ having the lowest $\Omega$ of $2.2 \times 10^{3}$. For a full description, see Figure S8.

It was essential to ascertain whether the printing technique implemented herein resulted in a complete and uniform coverage of $2 \mathrm{D}-\mathrm{MoS}_{2}$ onto the surface of an SPE. We, therefore, employed a Raman mapping technique encompassing the entire surface of a G-SPE or $2 \mathrm{D}-\mathrm{MoS}_{2}-\mathrm{SPE}_{400 \mathrm{~nm}}$. At each of the points within the Raman grid, a comparison was made between the observed intensity of the peak at $380 \mathrm{~cm}^{-1}$ (characteristic of $2 \mathrm{D}-\mathrm{MoS}_{2}$ ) and the underlying graphite peak at $1580 \mathrm{~cm}^{-1}$, thus allowing one to observe the coverage effect of the $2 \mathrm{D}-\mathrm{MoS}_{2}$. Figure 5 shows that increasing the percentage mass of $2 \mathrm{D}-\mathrm{MoS}_{2}$ within the graphitic ink, used to produce the $2 \mathrm{D}-\mathrm{MoS}_{2}-\mathrm{SPE}_{400 \mathrm{~nm}}$ surface, results in an increased intensity of the $380 \mathrm{~cm}^{-1}$ Raman peak, signifying that there is a positive correlation between the percentage of $2 \mathrm{D}-\mathrm{MoS}_{2}$ within the separate inks and the $2 \mathrm{D}-\mathrm{MoS}_{2}$ present on the electrode surfaces. The visible red (the Raman map of a G-SPE) coverage in Figure 5A signifies that the incorporation of a 5\% 2D-MoS into the graphitic ink is not a sufficient mass to result in a complete surface coverage. At $10 \% 2 \mathrm{D}-\mathrm{MoS}_{2}$ incorporation within the ink, there are no visible red points; we therefore propose that this is the mass at which complete coverage of the 
electrode surface by $\mathrm{MoS}_{2}$ is achieved. Note that because of the similarity between the $2 \mathrm{D}-\mathrm{MoS}_{2}$ nanosheets and the graphite/ binder present on the surface of an SPE, any attempt to visually assess the presence of $2 \mathrm{D}-\mathrm{MoS}_{2}$ on the $2 \mathrm{D}-\mathrm{MoS}_{2}-\mathrm{SPE}_{400 \mathrm{~nm}}$ surface was unsuccessful, as shown in Figure S9.

To ascertain the CS of the $2 \mathrm{D}-\mathrm{MoS}_{2}$-SPEs, 1000 repeat scans were carried out on a $20 \% 2 \mathrm{D}-\mathrm{MoS}_{2}-\mathrm{SPEs}_{400 \mathrm{~nm}}$, which acted as a representative example for all of the $2 \mathrm{D}-\mathrm{MoS}_{2}$-SPEs. This is a vital consideration, especially for the industrial applications, where stability and longevity are essential characteristics of an electrode material. It is evident upon the inspection of Figure $\mathrm{S} 10 \mathrm{~A}$ that the $20 \% 2 \mathrm{D}-\mathrm{MoS}_{2}-\mathrm{SPE}_{400 \mathrm{~nm}}$ displays remarkable stability with respect to its achievable current, as it goes from 41.24 to $41.34 \mu \mathrm{A}$ for the 1 st to the 1000th scan (based on the current at $-0.75 \mathrm{~V}$ and a cyclic voltammetry $(\mathrm{CV})$ potential range of 0 to $-1.4 \mathrm{~V}$ ). Note that a carbon-based electrode was used as a counter-electrode rather than the typical Pt electrode for the duration of this CS. This was to prevent any contamination of the working electrode by in situ deposition from the Pt counter-electrode by the mechanism described by Gottlieb et al., ${ }^{35}$ which would serve to convolute the observed results. Returning to Figure S10, there is a redox peak visible at approximately $-0.3 \mathrm{~V}$ on the 1000th scan, which is not visible on the 1st, 10th, and 100th scans. This can be attributed to the ORR occurring as oxygen is likely to have permeated the $0.1 \mathrm{M}$ $\mathrm{H}_{2} \mathrm{SO}_{4}$ electrolyte over the course of the CS experiment. ${ }^{10}$ Figure S10B shows the observed CVs of an SPE that had approximately $252 \mathrm{ng} \mathrm{cm}{ }^{-2}$ of $2 \mathrm{D}-\mathrm{MoS}_{2}$ drop-cast onto its surface and then subsequently underwent a CS test under identical conditions as implemented above. It is clear upon inspection of this figure that the HER onset potential became slightly more electronegative over the course of 1000 repeat scans, with the 1st scan having a HER onset of approximately $-480 \mathrm{mV}$ (vs SCE) compared with $-520 \mathrm{mV}$ (vs SCE) for the 1000 th scan. There is also a $21.9 \%$ reduction evident in the observed current (from $49.2 \mu \mathrm{A}$ at the 1 st scan to $38.4 \mu \mathrm{A}$ at the 1000th scan, based on the current at $-0.75 \mathrm{~V}$ and a CV potential range of 0 to $-1.4 \mathrm{~V}$ ). This reduction in the achievable current is likely a result of the $2 \mathrm{D}-\mathrm{MoS}_{2}$ delaminating from the electrode surface over the course of 1000 scans. To further explore the stability of the $20 \% 2 \mathrm{D}$ $\mathrm{MoS}_{2}-\mathrm{SPE}_{400 \mathrm{~nm}}$, we performed chronoamperometry at $-0.75 \mathrm{~V}$ for $36000 \mathrm{~s}$ as reported in Figure S10C. The achieved maximum current increased from $-30 \mu \mathrm{A}$ at $0 \mathrm{~s}$ to $37.4 \mu \mathrm{A}$ at $2500 \mathrm{~s}$, after which there was a more gradual increase in the current to $48.9 \mu \mathrm{A}$ at $36000 \mathrm{~s}$. Table S3 shows the elemental compositions, deduced using XPS, of a 20\% 2D-MoS $2-\mathrm{SPE}_{400 \mathrm{~nm}}$ pre and post 1000 repeat scans described above. Clearly, no contaminants were present that may have contributed to the prolonged current stability exhibited by the $2 \mathrm{D}-\mathrm{MoS}_{2}-\mathrm{SPE}_{400 \mathrm{~nm}}$, such as Pt. We, therefore, infer that the remarkable stability observed is due to the intrinsic properties of the $2 \mathrm{D}-\mathrm{MoS}_{2}-\mathrm{SPE}$ that arise owing to the anchoring of $2 \mathrm{D}-\mathrm{MoS}_{2}$ within the bespoke-formulated ink. It was essential to compare the CS of drop-casting 2D-MoS 2 onto the surface of a G-SPE to ascertain whether the incorporation of the $2 \mathrm{D}-\mathrm{MoS}_{2}$ into the bulk SPE ink offers an advantage in this respect. Given the results of the CS studies, it can be inferred that incorporating the $2 \mathrm{D}-\mathrm{MoS}_{2}$ into the bulk SPE ink (rather then drop-casting the 2D-MoS ${ }_{2}$ ) results in a greater stability of the achievable current.

The intrarepeatability of the $2 \mathrm{D}-\mathrm{MoS}_{2}-\mathrm{SPEs}_{400 \mathrm{~nm}}$ was also explored with three repeats. The percentage relative standard deviation (\% RSD) for the observed ORR onset potential and the number of electrons involved in the ORR pathway were observed to correspond to $2.30,4.14,4.57,4.66$, and $4.89 \%$ and $2.13,4.75,5.48,5.74$, and $5.82 \%$ for the G-SPE, 5, 10, 20, and $40 \% 2 \mathrm{D}-\mathrm{MoS}_{2}-\mathrm{SPEs}_{400 \mathrm{~nm}}$, respectively. There is clearly a trend of increasing \% RSD corresponding to an increase in the percentage of $2 \mathrm{D}-\mathrm{MoS}_{2}$ within the $2 \mathrm{D}-\mathrm{MoS}_{2}-\mathrm{SPEs}_{400 \mathrm{~nm}}$; however, these values are significantly less than $17.52 \%$ observed for a G-SPEs modified with approximately $252 \mathrm{ng}$ $\mathrm{cm}^{-2}$ of $2 \mathrm{D}-\mathrm{MoS}_{2}$ via drop-casting. We postulated the reasons for this in the Supporting Information.

Clearly, the 2D-MoS - -SPEs have numerous advantages over traditional carbon-based electrodes, such as their reproducibility, tailorability, and vast economy of scales, whilst also being highly electrocatalytic toward the ORR.

\section{CONCLUSIONS}

We have reported upon the production, characterization, and implementation of $2 \mathrm{D}-\mathrm{MoS}_{2}$ electrocatalytic inks that are herein utilized to produce SPEs/surfaces (2D-MoS $-\mathrm{SPE}$ ). Through tailoring the lateral width of the $\mathrm{MoS}_{2}$ flakes utilized in the $2 \mathrm{D}-\mathrm{MoS}_{2}$-SPE production from an average size ranging from approximately $400 \mathrm{~nm}$ to 2 and $6 \mu \mathrm{m}$, it was possible to optimize the $2 \mathrm{D}-\mathrm{MoS}_{2}$-SPE electrocatalytic activity toward the ORR. We observed a clear trend of increased ORR activity associated with the incorporation of a smaller $\mathrm{MoS}_{2}$ flake size. We prescribed this observation because of a higher ratio of electrocatalytic Mo sites, found at the active edges of the flake, available relative to the inert basal planes at smaller flakes.

Utilizing a mass ratio of $40 \%(400 \mathrm{~nm}) 2 \mathrm{D}-\mathrm{MoS}_{2}$ to $60 \%$ carbon ink to produce optimized 2D-MoS $-\mathrm{SPE}_{400 \mathrm{~nm}}$ results in an ORR onset potential, peak current, and average $n$ value of $+0.16 \mathrm{~V},-1.62 \mathrm{~mA} \mathrm{~cm}^{-2}$, and 4.29 , respectively. These values clearly show that the $40 \% 2 \mathrm{D}-\mathrm{MoS}_{2}-\mathrm{SPE}_{400 \mathrm{~nm}}$ is significantly more electrocatalytic toward the ORR than a typical graphitebased SPE. Most promising of all is the observation that at any of the optimized 5, 10, 20, and 40\% 2D-MoS $-\mathrm{SPEs}_{400 \mathrm{~nm}}$, the ORR reaction mechanism was occurring via the desirable fourelectron pathway $\left(\mathrm{H}_{2} \mathrm{O}\right.$ product) rather than the two-electron pathway $\left(\mathrm{H}_{2} \mathrm{O}_{2}\right.$ product). The $2 \mathrm{D}-\mathrm{MoS}_{2}-\mathrm{SPE}_{400 \mathrm{~nm}}$ were also shown to be electrochemically stable with regard to their signal output (current), with an optimized 20\% 2D-MoS 2 -SPEs displaying an increase of $0.21 \% \mu \mathrm{A}$ in their achievable current being observed over the course of 1000 repeat scans.

The technique in which we have fabricated $2 \mathrm{D}-\mathrm{MoS}_{2}$ incorporated inks and, subsequently, $2 \mathrm{D}-\mathrm{MoS}_{2}-\mathrm{SPEs}_{400 \mathrm{~nm}}$ can be readily extended as a template for industrial and research applications seeking to produce cheap, stable, and reproducible electrodes/surfaces that would display the unique and interesting electrochemical properties associated with a plethora of $2 \mathrm{D}$ nanomaterials that could be incorporated into an ink in the same manner as $2 \mathrm{D}-\mathrm{MoS}_{2}$ is herein shown to be capable of.

\section{ASSOCIATED CONTENT}

\section{Supporting Information}

The Supporting Information is available free of charge on the ACS Publications website at DOI: 10.1021/acsami.7b05104.

Additional characterization of the $\mathrm{MoS}_{2}$ powders, exploration of the 2D-MoS${ }_{2}-\mathrm{SPEs}_{400 \mathrm{~nm}}$ toward the HER including Tafel and turnover frequency calculations, repeatability studies of the $2 \mathrm{D}-\mathrm{MoS}_{2}-\mathrm{SPEs}_{400 \mathrm{~nm}}$, and an EIS study of the 2D-MoS ${ }_{2}$-SPEs (PDF) 


\section{AUTHOR INFORMATION}

\section{Corresponding Author}

*E-mail: c.banks@mmu.ac.uk. Phone: ++(0)1612471196. Fax: $++(0) 1612476831$. Website: www.craigbanksresearch.com.

ORCID $\odot$

Craig E. Banks: 0000-0002-0756-9764

Notes

The authors declare no competing financial interest.

\section{ACKNOWLEDGMENTS}

Funding from the Engineering and Physical Sciences Research Council (reference: EP/N001877/1) and a British Council Institutional Grant Link (no. 172726574) is acknowledged.

\section{REFERENCES}

(1) Hinnemann, B.; Moses, P. G.; Bonde, J.; Jørgensen, K. P.; Nielsen, J. H.; Horch, S.; Chorkendorff, I.; Nørskov, J. K. Biomimetic Hydrogen Evolution: $\mathrm{MoS}_{2}$ Nanoparticles as Catalyst for Hydrogen Evolution. J. Am. Chem. Soc. 2005, 127, 5308-5309.

(2) Schultz, M. G.; Diehl, T.; Brasseur, G. P.; Zittel, W. Air Pollution and Climate-Forcing Impacts of a Global Hydrogen Economy. Science 2003, 302, 624-627.

(3) Schmidt, T. J.; Paulus, U. A.; Gasteiger, H. A.; Behm, R. J. The Oxygen Reduction Reaction on a Pt/Carbon Fuel Cell Catalyst in the Presence of Chloride Anions. J. Electroanal. Chem. 2001, 508, 41-47.

(4) Banham, D.; Ye, S.; Pei, K.; Ozaki, J.-I.; Kishimoto, T.; Imashiro, Y. A Review of the Stability and Durability of Non-Precious Metal Catalysts for the Oxygen Reduction Reaction in Proton Exchange Membrane Fuel Cells. J. Power Sources 2015, 285, 334-348.

(5) Gao, M.-R.; Liang, J.-X.; Zheng, Y.-R.; Xu, Y.-F.; Jiang, J.; Gao, Q.; Li, J.; Yu, S.-H. An Efficient Molybdenum Disulfide/Cobalt Diselenide Hybrid Catalyst for Electrochemical Hydrogen Generation. Nat. Commun. 2015, 6, 5982.

(6) Li, G.; Zhang, D.; Qiao, Q.; Yu, Y.; Peterson, D.; Zafar, A.; Kumar, R.; Curtarolo, S.; Hunte, F.; Shannon, S.; Zhu, Y.; Yang, W.; Cao, L. All The Catalytic Active Sites of $\mathrm{MoS}_{2}$ for Hydrogen Evolution. J. Am. Chem. Soc. 2016, 138, 16632-16638.

(7) Gewirth, A. A.; Thorum, M. S. Electroreduction of Dioxygen for Fuel-Cell Applications: Materials and Challenges. Inorg. Chem. 2010, 49, 3557-3566.

(8) Liu, Y.; Yue, X.; Li, K.; Qiao, J.; Wilkinson, D. P.; Zhang, J. PEM Fuel Cell Electrocatalysts Based on Transition Metal Macrocyclic Compounds. Coord. Chem. Rev. 2016, 315, 153-177.

(9) Gao, M.-R.; Xu, Y.-F.; Jiang, J.; Zheng, Y.-R.; Yu, S.-H. Water Oxidation Electrocatalyzed by an Efficient $\mathrm{Mn}_{3} \mathrm{O}_{4} / \mathrm{CoSe}_{2}$ Nanocomposite. J. Am. Chem. Soc. 2012, 134, 2930-2933.

(10) Rowley-Neale, S. J.; Fearn, J. M.; Brownson, D. A. C.; Smith, G. C.; Ji, X.; Banks, C. E. 2D Molybdenum Disulphide (2D-MoS 2 ) Modified Electrodes Explored Towards the Oxygen Reduction Reaction. Nanoscale 2016, 8, 14767-14777.

(11) Jaouen, F.; Proietti, E.; Lefêvre, M.; Chenitz, R.; Dodelet, J.-P.; Wu, G.; Chung, H. T.; Johnston, C. M.; Zelenay, P. Recent Advances in Non-Precious Metal Catalysis for Oxygen-Reduction Reaction in Polymer Electrolyte Fuel Cells. Energy Environ. Sci. 2011, 4, 114-130.

(12) Gubler, L.; Dockheer, S. M.; Koppenol, W. H. Radical (HO•, $\mathrm{H} \bullet$ and HOO•) Formation and Ionomer Degradation in Polymer Electrolyte Fuel Cells. J. Electrochem. Soc. 2011, 158, B755-B769.

(13) Uosaki, K.; Elumalai, G.; Noguchi, H.; Masuda, T.; Lyalin, A.; Nakayama, A.; Taketsugu, T. Boron Nitride Nanosheet on Gold as an Electrocatalyst for Oxygen Reduction Reaction: Theoretical Suggestion and Experimental Proof. J. Am. Chem. Soc. 2014, 136, 6542-6545.

(14) Gao, M.-R.; Xu, Y.-F.; Jiang, J.; Yu, S.-H. Nanostructured Metal Chalcogenides: Synthesis, Modification, and Applications in Energy Conversion and Storage Devices. Chem. Soc. Rev. 2013, 42, 29863017.
(15) Deng, D.; Novoselov, K. S.; Fu, Q.; Zheng, N.; Tian, Z.; Bao, X. Catalysis with Two-Dimensional Materials and their Heterostructures. Nat. Nanotechnol. 2016, 11, 218-230.

(16) Suresh, C.; Mutyala, S.; Mathiyarasu, J. Support Interactive Synthesis of Nanostructured $\mathrm{MoS}_{2}$ Electrocatalyst for Oxygen Reduction Reaction. Mater. Lett. 2016, 164, 417-420.

(17) Huang, H.; Feng, X.; Du, C.; Wu, S.; Song, W. Incorporated Oxygen in $\mathrm{MoS}_{2}$ Ultrathin Nanosheets for Efficient ORR Catalysis. $J$. Mater. Chem. A 2015, 3, 16050-16056.

(18) Foster, C. W.; Kadara, R. O.; Banks, C. E. Screen-Printing Electrochemical Architectures, 1st ed.; Springer International Publishing: Germany, 2016.

(19) Sigma-Aldrich. http://www.sigmaaldrich.com/catalog/product/ aldrich/804169? lang=en\&region=GB (accessed Dec 5, 2016).

(20) Sigma-Aldrich. http://www.sigmaaldrich.com/catalog/product/ aldrich/234842? lang=en\&region=GB (accessed Jan 3, 2017).

(21) Sigma-Aldrich. http://www.sigmaaldrich.com/catalog/product/ aldrich/69860?lang=en\&region=GB\&gclid=Cj0KEQiAtK3DBRCBxt Y x d u q 5 p 4 B E i QA b Fi a P R s U - t F y w f A X j 963 r sUoDCdqX4Jdjkp9EzmUix5kq8aAqYc8P8HAQ (accessed Jan 3, 2017).

(22) Randviir, E. P.; Banks, C. E. The Oxygen Reduction Reaction at Graphene Modified Electrodes. Electroanalysis 2014, 26, 76-83.

(23) Gara, M.; Compton, R. G. Activity of Carbon Electrodes Towards Oxygen Reduction in Acid: A Comparative Study. New J. Chem. 2011, 35, 2647-2652.

(24) Liu, K.; Zhang, L.; Cao, T.; Jin, C.; Qiu, D.; Zhou, Q.; Zettl, A.; Yang, P.; Louie, S. G.; Wang, F. Evolution of Interlayer Coupling in Twisted Molybdenum Disulfide Bilayers. Nat. Commun. 2014, 5, 4966.

(25) Tao, L.; Long, H.; Zhou, B.; Yu, S. F.; Lau, S. P.; Chai, Y.; Fung, K. H.; Tsang, Y. H.; Yao, J.; Xu, D. Preparation and Characterization of Few-Layer $\mathrm{MoS}_{2}$ Nanosheets and their good Nonlinear Optical Responses in the PMMA Matrix. Nanoscale 2014, 6, 9713-9719.

(26) Hu, K.; Hu, X.; Xu, Y.; Sun, X.; Jiang, Y. Tribology of $\mathrm{MoS}_{2-}$ Based Nanocomposites. In Tribology of Nanocomposites; Davim, J. P., Ed.; Springer Berlin Heidelberg: Heidelberg, 2013; pp 41-60.

(27) Li, H.; Zhang, Q.; Yap, C. C. R.; Tay, B. K.; Edwin, T. H. T.; Olivier, A.; Baillargeat, D. From Bulk to Monolayer $\mathrm{MoS}_{2}$ : Evolution of Raman Scattering. Adv. Funct. Mater. 2012, 22, 1385-1390.

(28) Rowley-Neale, S. J.; Brownson, D. A. C.; Smith, G. C.; Sawtell, D. A. G.; Kelly, P. J.; Banks, C. E. 2D Nanosheet Molybdenum Disulphide $\left(\mathrm{MoS}_{2}\right)$ Modified Electrodes Explored Towards the Hydrogen Evolution Reaction. Nanoscale 2015, 7, 18152-18168.

(29) Lee, C.; Yan, H.; Brus, L. E.; Heinz, T. F.; Hone, J.; Ryu, S. Anomalous Lattice Vibrations of Single- and Few-Layer $\mathrm{MoS}_{2}$. ACS Nano 2010, 4, 2695-2700.

(30) Paulus, U. A.; Wokaun, A.; Scherer, G. G.; Schmidt, T. J.; Stamenkovic, V.; Radmilovic, V.; Markovic, N. M.; Ross, P. N. Oxygen Reduction on Carbon-Supported $\mathrm{Pt}-\mathrm{Ni}$ and $\mathrm{Pt}-\mathrm{Co}$ Alloy Catalysts. J. Phys. Chem. B 2002, 106, 4181-4191.

(31) Khan, A. F.; Randviir, E. P.; Brownson, D. A. C.; Ji, X.; Smith, G. C.; Banks, C. E. 2D Hexagonal Boron Nitride (2D-hBN): A New Electrocatalyst for the Oxygen Reduction Reaction. Electroanalysis 2016, 31, 1521-4109.

(32) Brownson, D. A. C.; Banks, C. E. The Handbook of Graphene Electrochemistry, 1st ed.; Springer: London, 2014.

(33) Kaskiala, T. Determination of Oxygen Solubility in Aqueous Sulphuric Acid Media. Miner. Eng. 2002, 15, 853-857.

(34) Han, P.; Bartels, D. M. Temperature Dependence of Oxygen Diffusion in $\mathrm{H}_{2} \mathrm{O}$ and $\mathrm{D}_{2} \mathrm{O}$. J. Phys. Chem. 1996, 100, 5597-5602.

(35) Gottlieb, E.; Kopeć, M.; Banerjee, M.; Mohin, J.; Yaron, D.; Matyjaszewski, K.; Kowalewski, T. In-Situ Platinum Deposition on Nitrogen-Doped Carbon Films as a Source of Catalytic Activity in a Hydrogen Evolution Reaction. ACS Appl. Mater. Interfaces 2016, 8, 21531-21538.

(36) Illathvalappil, R.; Unni, S. M.; Kurungot, S. Layer-Separated $\mathrm{MoS}_{2}$ Bearing Reduced Graphene Oxide Formed by an in Situ Intercalation-Cum-Anchoring Route Mediated by $\mathrm{Co}(\mathrm{OH})_{2}$ as a Pt- 
free Electrocatalyst for Oxygen Reduction. Nanoscale 2015, 7, 1672916736.

(37) Zhou, J.; Xiao, H.; Zhou, B.; Huang, F.; Zhou, S.; Xiao, W.; Wang, D. Hierarchical $\mathrm{MoS}_{2}-\mathrm{rGO}$ Nanosheets with High $\mathrm{MoS}_{2}$ Loading with Enhanced Electro-Catalytic Performance. Appl. Surf. Sci. 2015, 358 Part A, 152-158.

(38) Wang, T.; Zhuo, J.; Chen, Y.; Du, K.; Papakonstantinou, P.; Zhu, Z.; Shao, Y.; Li, M. Synergistic Catalytic Effect of $\mathrm{MoS}_{2}$ Nanoparticles Supported on Gold Nanoparticle Films for a Highly Efficient Oxygen Reduction Reaction. ChemCatChem 2014, 6, 18771881.

(39) Zhao, K.; Gu, W.; Zhao, L.; Zhang, C.; Peng, W.; Xian, Y. $\mathrm{MoS}_{2} /$ Nitrogen-Doped Graphene as Efficient Electrocatalyst for Oxygen Reduction Reaction. Electrochim. Acta 2015, 169, 142-149.

(40) Yu, B.; Min, H.; Wu, H.; Wang, S.; Ding, Y.; Wang, G. Production of $\mathrm{MoS}_{2} / \mathrm{CoSe}_{2}$ Hybrids and their Performance as Oxygen Reduction Reaction Catalysts. J. Mater. Sci. 2017, 52, 3188-3198.

(41) Zuo, L.-X.; Jiang, L.-P.; Zhu, J.-J. A Facile Sonochemical Route for the Synthesis of $\mathrm{MoS}_{2} / \mathrm{Pd}$ Composites for Highly Efficient Oxygen Reduction Reaction. Ultrason. Sonochem. 2017, 35 Part B, 681-688.

(42) Bothra, P.; Pandey, M.; Pati, S. K. Size-Selective Electrocatalytic Activity of $(\mathrm{Pt}) \mathrm{n} / \mathrm{MoS}_{2}$ for Oxygen Reduction Reaction. Catal. Sci. Technol. 2016, 6, 6389-6395.

(43) Huang, H.; Feng, X.; Du, C.; Song, W. High-quality phosphorus-doped $\mathrm{MoS}_{2}$ ultrathin nanosheets with amenable ORR catalytic activity. Chem. Commun. 2015, 51, 7903-7906.

(44) Chua, X. J.; Luxa, J.; Eng, A. Y. S.; Tan, S. M.; Sofer, Z.; Pumera, M. Negative Electrocatalytic Effects of p-Doping Niobium and Tantalum on $\mathrm{MoS}_{2}$ and $\mathrm{WS}_{2}$ for the Hydrogen Evolution Reaction and Oxygen Reduction Reaction. ACS Catal. 2016, 6, 5724-5734. 